\title{
ВЛИЯНИЕ ТВОРЧЕСКОЙ ЭЛИТЫ НА КУЛЬТУРНУЮ ПОЛИТИКУ РОССИИ ХХІ ВЕКА
}

\section{THE INFLUENCE OF THE CREATIVE ELITE ON THE CULTURAL POLICY OF RUSSIA IN THE XXI CENTURY}

\section{Golysheva}

Summary: The author examines the transformation of cultural policy in the historical aspect, focusing on important transitional events. The article presents the results of the author's research of the creative elite in culture, forming a portrait of a representative of the modern creative elite, who is proclaimed the moderator of the industry.

The paper identifies the main mechanisms of influence of the creative elite in culture on cultural policy, which affect the development of not only the industry, but also the state as a whole. The risks of using the project approach in the reproduction of the new creative elite of the cultural sphere are revealed.

Keywords: creative elite, creative elite of the sphere of culture, cultural policy, mechanisms of influence.
Голышева Инна Валерьевна

Аспирант, Российская академия народного хозяйства и государственной службы при Президенте РФ, г. Москва, Inngolysheva@yandex.ru

Аннотация: Автор рассматривает трансформацию культурной политики в историческом аспекте, акцентируя внимание на важных переходных событиях. В статье проводятся результаты авторского исследования творческой элиты в культуре, формируется портрет представителя современной творческой элиты, провозглашаемого модератором отрасли.

В работе обозначены основные механизмы влияния творческой элиты в культуре на культурную политику, которые воздействуют на развитие не только отрасли, но и государства в целом. Выявлены риски использования проектного подхода в воспроизведении новой творческой элиты сферы культуры.

Ключевые слова: творческая элита, творческая элиты сферы культуры, культурная политика, механизмы влияния.
$\mathrm{P}$ ассматривая влияние культурной политики в динамике исторических процессов, можно увидеть ценностно-смысловые изменения не только в обществе, но и в культурных институциях, являющихся исполнителем этой политики. Если отправной точкой анализа считать советский период, то культурная политика неразрывно связана с агитационными действиями и представлена активной пропагандисткой программой, осуществлявшейся идеологическим отделом ЦК КПСС. Культура воспринималась как явление - прямолинейное, лишенное многообразий и противоречий, культурный прогресс становился процессом нарастающего упрощения [2, с. 33].

В основах законодательства Российской Федерации о культуре 1992 года большое внимание уделяется гуманизации общества и сохранению национальной самобытности народов [20]. По мнению Арнольдова А.И. в стратегии культурной политики ведущее место занимает создание комплексной программы освоения общечеловеческих ценностей [2, с.237-238.]. Этот период осложняется некоторыми факторами: отсутствует привлечение широких слоев населения в культуру, финансирование сферы осуществляется по остаточному принципу, по этой же причине продолжается сокращение количества таких ведомственных учреждений культуры как, библиотеки и клубные центры. В целом происходит ухудшение качества профильной деятельности основной массы предприятий социокультурной сферы.

В 2000 годах культурная политика России была сосредоточена на охране культурного наследия [9, с.101]. В работе Садохина А.П. упоминается, что динамика культуры сопровождается процессами изменений и обновлений, происходит трансформация культурных форм [8, с.151].

Указы Президента В.В. Путина, именуемые «майскими», на период выполнения с 2012 по 2020 год стали катализатором формирования следующих государственных документов для развития отрасли культуры, таких как: Основы государственной культурной политики 2014 года, где государство впервые провозглашает культуру не только главнейшим фактором развития страны в социально-экономическом плане, но и возводит ее в ранг стратегических «национальных приоритетов... гарантов сохранения единого культурного пространства и территориальной целостности страны» [18]; Стратегия государственной культурной политики на период до 2030 года, принятая в 2016 году, основными целями которой являются: сохранение гражданской идентичности, создание условий для воспитания граждан и обеспечение доступа к культурным благам [19].

Первым шагом к концептуализации и формулированию основ, «в целях привлечения внимания общества 
к вопросам развития культуры, сохранения культурноисторического наследия и роли российской культуры во всем мире», стал Указ президента РФ «О проведении в Российской Федерации Года культуры» [16]. Ряд таких значимых документов для отрасли, отразились и в деятельности основной государственной политики, так 2015 год, был объявлен, «Годом русской литературы», а 2016 год, посвящен российскому кино.

В новом цикле «майских указов» 2018 года президент России В.В. Путин поставил задачи по созданию новых инфраструктурных объектов культуры в крупных городах и организации досуга в сельской местности [17], наметилась децентрализация культурных благ. Комплекс мероприятий по стратегическому развитию и приоритетным проектам, сформировался в национальные проекты (программы) и охватил 12 направлений жизнедеятельности. Реализация национального проекта «Культура» в период с 2019 по 2024 г, включает в себя три глобальных направления: создание и реконструкция инфраструктуры, предоставление возможности реализации творческого потенциала и повышение квалификации, цифровизация отрасли, а именно увеличение числа обращений к цифровым ресурсам в сфере культуры [15].

Завершая исторический обзор векторов развития культурной политики советской и современной России, хочется уделить внимание работе Арнольдова А.И., обозначивший в 1993 году, культурную политику для руководства страны, как инструмент реагирования на культурно-духовные реалии жизни общества, благодаря которому возможно создавать эффективные механизмы регулирования и координации культуры с социальноэкономическими сторонами жизни [2,с. 238].

Влияние культурной политики на общественность и в большей степени на развитие отрасли культуры безусловно существует, в работе и приведенных материалах выше прослеживается причинно-следственная связь, принимаемых решений и в последствии создание нормативно-правовых актов. В то же время следует отметить, путь возникновения, «сотворения» столь важных документов, стратегий, основ, паспортов, начинается с человека. Индивида, обладающего не только знаниями, профессиональной компетентностью, но и соответствующего завышенным критериальным требованиям и характеристикам. В основу понимания индивида и для отображения социокультурного портрета представителя современной творческой элиты, обратимся к толкованию термина современными авторами и маркерам отличия творческой элиты от нетворческой, а также её функциональное предназначение. Большинство исследователей наделяет творческую элиту, уникально-значимым ресурсом, к этому пониманию относится не только создание творческого продукта, в том числе различное влияние на органы власти для реализации заявленного потенциала. Одним из маркеров отличия творческой элиты от нетворческой элиты, заложено в морфологии термина. Определяя более узкий подход к рассмотрению творческой элиты её отличий и функциональных особенностей, проанализируем творческую элиту в культуре.

Основой творческой элиты является - творчество, под данным термином мы понимаем деятельность, порождающая нечто новое, никогда ранее не бывшее [10, с. 71]. Профессор Шелонаев С.И., разделяя мнение Ю.А. Левады [6], наделяет данную социальную группу ресурсными возможностями, и способностью хранения, воспроизводства и умножения творческого потенциала. В работах Валеевой 3.Р., в духовно-творческой элите, выделяется культурная идентичность, влияющая и предопределяющая социальную активность индивида. Представители духовно-творческой элиты вносят общественно значимый вклад в создание ценностей культуры [3]. Также, в исследовательских работах Ю.В. Китова и С.Л. Гертнер элита определяется, как социальная группа, носитель культуры, способная принимать решения в рамках определенного территориального присутствия и обладающая ресурсами для их осуществления [5]. В исследовании 2021 года Аксенова П.В. при раскрытии содержания интеллектуальной элиты, большое внимание уделяет ценностно-нормативной парадигме и подробной функциональной характеристике [1].

Объединяя и анализируя вышеизложенные утверждения, невозможно избежать обращения к вызовам нынешнего социокультурного пространства, где представитель творческой элиты XXI века в культуре, является не просто многокомпонентным сложным субъектом культуры, а в первую очередь, модератором отрасли, творческого объединения, идейного проекта.

\section{Творческая элита в культурной политике}

Большое значение приобретает причастность творческой элиты к культурной политике, в связи с этим, необходимо обозначить механизмы влияния творческой элиты культурной сферы на культурную политику государства: 1. Инновационное созидание - основа, создание новых идей, продуктов творчества, отвечающие современным вызовам времени, поддерживающие продуктивную деятельность всей сферы и внедряющие инновационные инструменты для развития, тиражирования, формирования тенденций (трендов). Как пример, данного влияния, можно привести, открытие в 2013 году театрального «Гоголь-центра», ставшего, на тот момент, флагманом инновационных преобразований в театральном искусстве, осуществивший коллаборацию театра, кино, концертной и выставочной деятельности, лекториума, дискуссионных клубов. 2. Стратегическое транслирование - целенаправленное решение поставленных 
задач в культуре, также решение некоторых вопросов в рамках проектов, с определенным временным ресурсом и учётом основного содержания и сути проектной деятельности. Одним из ярчайших примеров данного влияния, можно обозначить обращение пианистки, общественного деятеля Екатерины Мечетиной к президенту Путину В.В. на заседании Совета по культуре и искусству [14]. Суть обращения сводилась к запрету включения детских школ искусств (ДШИ) в систему персонифицированного финансирования дополнительного образования (ПФДО), как несоответствующую уставной деятельности и задачам ДШИ, обреченного на исчезновение первой ступени профессионального образования в сфере культуры. Вследствие чего детские школы искусств получили особый статус в системе, о чем свидетельствуют изменения внесенные в Федеральный закон [13]. 3. Историческая идентичность - сохранение, транслирование и передача накопленного культурно - исторического опыта в аспекте образования, профессионального обучения, просветительства. Как пример, можно обозначить запуск ряда мероприятий, в рамках программы «Волонтеры культуры», направленных на обеспечение поддержки добровольческих движений, в том числе в сфере сохранения культурного наследия народов Российской Федерации, включая деятельность по сохранению исторического облика малых городов [12]. 4. Национальная идеология - позиционирование национальной культуры и её достижений на внутренний и внешний социокультурный мир. Русский балет, художественная литература, живопись, музыкальное наследие, являются не только визитными карточками страны и русского искусства, а также инструментами «мягкой силы» во внешней политике государства [4, с. 417].

Учитывая, данные механизмы влияния на культурную политику, творческую элиту в культуре можно определить как, - профессионально реализованные представители творческой сферы, которые имеют инструменты воздействия на культурную среду, посредством транслирования и внедрения идей и смыслов, а также являются организаторами либо участниками создания уникального творческого предложения.

Творческая элита явилась создателем столь стратегически важных национальных документов для отрасли, таких как: Основы государственной культурной политики; Стратегия государственной культурной политики на период до 2030 года.

В эту группу входили не только авторы документов, но и творческая элита сферы культуры регионального и общественного уровня. Так, влияние на итоговый текст Основ государственной культурной политики оказали: решение круглого стола Уральского федерального округа по обсуждению проекта Основ государственной культурной политики; обсуждения с Московского общественного форума, региональные обсуждения (Нижний
Новгород, Ханты-Мансийск, Великий Новгород, Омск, Пятигорск, Волгоградская область). Некоторые поправки носили рекомендательный характер, такие как: рекомендации к проекту Основ государственной культурной политики, составленные по результатам общественных обсуждений в Федеральных округах и городах Федерального значения, в дальнейшем принятые на круглом столе в Общественной палате РФ.

В обсуждении проекта документа в Министерстве культуры приняли участие: авторитетные деятели культуры, политики, образования; профессорско-управленческий состав ведущих ВУЗов; философское сообщество [11].

При формировании другого стратегически важного документа паспорта Национального проекта «Культура» была создана новая институция, проектный офис при Министерстве культуры ФГБУК «Роскультупроект» (Центр культурных стратегий и проектного управления).

\section{В^ияние проектной деятельности}

Особое внимание необходимо уделить влиянию проектной деятельности в формировании современной стратегии развития культурной политики государства. История возникновения метода проектов начинается в США во второй половине XIX века и основывается на теории прагматичной педагогики по принципу «обучение посредством делания» [7, с.312]. Основателем явился американский философ и педагог Дж. Дьюи. «Метод проблем», как называли его, был связан с идеями гуманистического направления в философии и образования, был представлен как комплекс мероприятий, направленный на достижение цели, будь то модернизация, создание или поддержание чего-либо, в определенных пространственно-временных и ресурсных границах. Стоит отметить, что проектные мероприятия, реализующиеся на территории России, являются копированием западной модели и применяются на федеральном уровне.

Данный подход стал особенно актуален в России, когда отраслевые стратегические нормативно-правовые акты обрели название - национальные проекты. Большинство мероприятий, включенных в национальный проект «Культура», имеют временной характер, такие как: реставрация зданий; оснащение музыкальными инструментами; увеличение посещаемости; цифровизация отрасли и оцифровка книжных фондов и другие. Мероприятия федерального проекта «Творческие люди» в составе национального проекта «Культура», предоставляют возможность реализации творческого потенциала некоммерческому сектору, что приводит к культурному разнообразию, обеспечивает присутствие других акторов, влияющих на модернизацию культурной политики России и перемены в социокультурной среде. В будущем участники национальных проектов, федеральных 
конкурсов, лидеры культурных инноваций и изменений, перейдут в состав творческой элиты в культуре. Только необходимо учитывать, что становление индивидуума, отвечающего всем критериям и характеристикам данной социальной группы, не является процедурой, умещающейся в пространственно-временные границы, так как процесс становления личности, представителя творческой элиты в сфере культуры сложный и многоплановый, иначе появляются риски профессионального падения компетенций и снижение духовно-нравственного внутреннего содержания представителя, в связи с отсутствием системы развития и профессионального роста.

\section{Зак^ючение}

Современная творческая элита играет особую роль в реализации культурной политики России, в результате своей креативной деятельности и инициативности, оказывает содействие в организации и создании нового социокультурного пространства. Несмотря на новые условия активных изменений как во внутренних процессах, так и во внешнем политическом международном взаимодействии, именно творческая элита является модератором развития отрасли и влияет на внешний социокультурный мир, посредством определенных механизмов воздействия.

Усиливающийся научный интерес к творческой элите, её роли в культурных трансформациях, а также влияние на культурную политику, еще раз подчеркивает необходимость и важность исследований данного вопроса, выявление и предупреждение рисков формирования творческой элиты сферы культуры не только в настоящем времени, но в первую очередь ориентируясь на долгосрочную перспективу.

\section{ЛИТЕРАТУРА}

1. Аксенов П.В. Генетический детерминизм в социокультурных исследованиях феномена интеллектуальной элиты: критический анализ / П. В. Аксенов // Инновационное развитие науки: фундаментальные и прикладные проблемы: монография / П. В. Аксенов [и др.]. - Петрозаводск: МЦНП «Новая наука», 2020. - C. 5-21.

2. Арнольдов А.И. Введение в культурологию (новая расширенная редакция). Учебное пособие-М: Народная академия культуры и общечеловеческих ценностей, 1993. С.352.

3. Валеева 3.Р. Духовно-творческая элита как объект социально-философского исследования. - Казань: Изд-во КГУКИ, 2007. - 40 с.

4. Ефанова Елена Владимировна Инструменты «мягкой силы» во внешней политике государства // Вестник РУДН. Серия: Политология. 2018. №3. C. 417-426.

5. Культурные интересы современной элиты РС (Я) как выражение ее субъектности (на примере социологического исследования) / Игнатьева С.С., Китов Ю.В. // Современная культура Российской Арктики: субъекты, художественно-проектные и цифровые практики: Коллективная монография / Арктический гос. институт культуры и искусств; Науч. ред. О.В. Шлыкова. - Новосибирск: Наука, 2019. - С.118-125.

6. Левада Ю.А. Элитарные структуры В советской и постсоветской ситуации // Общественные науки и современность. 2007. № 6. С. 5-15.

7. Пеньковских Елена Анатольевна Метод проектов в отечественной и зарубежной педагогической теории и практике // Вопросы образования. 2010 . №4. C.307-318.

8. Садохин А.П. Культурология: теория и история культуры: Учебное пособие. — М.: Эксмо, 2007. (Образовательный стандарт XXI). С.-624.

9. Флиер А.Я. Культурология для культурологов: Учебное пособие для магистрантов и аспирантов, докторантов и соискателей, а также преподавателей культурологии. - М.: Академический Проект, 2000.—C.-496.

10. Шелонаев С.И. Технологии репутационного менеджмента: творческая элита. - СПб.: 000 «Книжный Дом», 2007. - С.212.

11. Обсуждения проекта документа «Основы государственной культурной политики» от $12.05 .2014 \mathrm{https}: / /$ culture.gov.ru/documents/project-documentpublic-discussions-1205140/

12. Программа «Волонтеры культуры» в рамках федерального проекта «Творческие люди» Национального проекта «Культура» httрs://волонтерыкультуры. $\mathrm{p} \phi$ /national-project-section

13. Федеральный закон от 24.03.2021 N 51-Ф3 «0 внесении изменений в Федеральный закон «0б образовании в Российской Федерации»

14. Заседание Совета по культуре и искусству при Президенте 27.10.2020 года

15. Паспорт национального проекта «Культура» (утв. президиумом Совета при Президенте РФ по стратегическому развитию и национальным проектам, протокол от 24.12.2018 N 16)

16. Указ Президента Российской Федерации от 22.04.2013 г. № 375 «0 проведении в Российской Федерации Года культуры»

17. Указ Президента Российской Федерации от 07.05.2018 г. № 204 «0 национальных целях и стратегических задачах развития Российской Федерации на период до 2024 года»

18. Указ Президента РФ от 24 декабря 2014 г. N 808 «0сновы государственной культурной политики»

19. Распоряжение Правительства РФ от 29.02.2016 N 326-р «0б утверждении Стратегии государственной культурной политики на период до 2030 года»

20. «0сновы законодательства Российской Федерации о культуре» 0т 09.10.1992 N 3612-1

(с) Голышева Инна Валерьевна (Inngolysheva@yandex.ru).

Журнал «Современная наука: актуальные проблемы теории и практики» 